\title{
COVID-19 Pandemisi Sürecinde Bireylerin Beslenme Davranışlarının ve Ortorektik Eğilimlerinin Değerlendirilmesi
}

\author{
Evaluation of Nutritional Behaviors and Orthorexic Tendency of Individuals During the \\ COVID-19 Pandemic Process
}

\author{
Özlem Özpak Akkuş , Esma Asil², Mustafa Volkan Yılmaz ${ }^{3}$
}

Geliş tarihi/Received: 12.09.2021 • Kabul tarihi/Accepted: 28.12.2021

\section{ÖZET}

Amaç: Bu çalışma, pandemi sürecinin ortoreksiya nervoza (ON) üzerindeki etkilerinin anlaşlabilmesi amacıyla, ON eğilimi olan bireyler ile ilişkili faktörlerin belirlenmesi ve bu bireylerin yeme davranışlarının değerlendirilmesi amacıyla yapılmıştır.

Bireyler ve Yöntem: Bu kesitsel çalışma çevrimiçi olarak hazırlanmış anket yardımıyla 19 yaş üzeri, kronik hastalığı ve COVID-19 öyküsü olmayan, gönüllü 699 yetişkin bireyin katılımıyla gerçekleştirilmiştir. Oluşturulmuş anket formunda bireylere ilişkin bazı genel bilgiler ve antropometrik ölçümler ile beslenme alışkanlıklarına ilişkin bilgiler toplanmıştır. Ayrıca ORTO-15 ölçeği ile bireylerin ortorektik eğilimleri belirlenmiş̧ir. Araştırma verileri SPSS programında değerlendirilmiştir.

Bulgular: Çalışmaya \%21.7’si erkek, \%78.3'ü kadın olmak üzere toplam 699 birey dahil edilmiştir. Çalışmaya katılan bireylerin \%68.2'sinde ortorektik eğilim saptanmış olup, erkeklerde (\%75), çalışanlarda (\%76.6), lisansüstü mezunlarında (\%79.5) ve normal vücut ağırlığına sahip olanlarda (\%76.1) ortorektik eğilimin daha yüksek olduğu belirlenmiştir ( $\mathrm{p}<0.05)$. Ortorektik eğilimin tüketilen yiyecek miktarı, evde yemek yeme sıklığı, yemek siparişi verme sıklığı, vitamin ve mineral tüketimleri, ana ve ara öğün tüketimleri gibi bazı beslenme alışkanlıklarını etkilemediği bulunmuştur ( $p>0.05$ ). Yapılan regresyon analizi sonuçlarına göre bireylerin ortorektik skor puanını, süt-yoğurt, tavuk ve şeker tüketiminde yaşanan değişimlerin arttırdığı saptanmıştır $(\mathrm{p}<0.05)$.

Sonuç: Sonuç olarak COVID-19 pandemi sürecinde bireylerin yüksek düzeyde ortorektik eğilime sahip oldukları ve bu eğilimin yüksek eğitim seviyesine sahip ideal vücut ağırlığına yakın olan bireylerde daha fazla olduğu belirlenmiştir. Pandemi gibi stresin fazla olduğu dönemde gelişen yeme bozuklukları uzun vadeli olabileceği için bu beslenme bozukluklarının zamanında teşhis edilmesi ve bireylere bu konuda gereken beslenme tedavisinin verilmesi önemlidir.

Anahtar kelimeler: Ortoreksiya nervoza, beslenme davranışı, COVID-19 pandemisi

\footnotetext{
ABSTRACT

1. Toros Üniversitesi Sağlık Bilimleri Fakültesi Beslenme ve Diyetetik Bölümü, Mersin, Türkiye • (ㅇ https://orcid.org/0000-0002-1471-8000

2. İletişim/Correspondence: Ankara Üniversitesi, Sağlık Bilimleri Fakültesi Beslenme ve Diyetetik Bölümü, Ankara, Türkiye

E-posta: energin@health.ankara.edu.tr • (1) https://orcid.org/0000-0003-0809-4008
}

Aim: This study was carried out to understand the effects of the pandemic process on orthorexia nervosa (ON), to determine the factors associated with individuals with ON tendency, and to evaluate the eating behaviors of these individuals.

3. Ankara Üniversitesi, Sağlık Bilimleri Fakültesi Beslenme ve Diyetetik Bölümü, Ankara, Türkiye • (1) https://orcid.org/0000-0002-7411-134X 
Subjects and Method: This cross-sectional study was carried out by using an online questionnaire, with the participation of 699 voluntary adult individuals over the age of 19, without chronic disease and COVID-19 history. In the created questionnaire form, some general information about the individuals, self-reported anthropometric measurements, and information about their eating habits were collected. In addition, the orthorexic tendencies of individuals were determined with the ORTO-15 scale. The research data were evaluated in the SPSS program.

Results: A total of 699 individuals, $21.7 \%$ male and $78.3 \%$ female, were included in the study. The Orthorexic tendency was detected in $68.2 \%$ of the individuals. It was determined that orthorexic tendency was higher in males (75\%), employed (76.6\%), postgraduate graduates (79.5\%), and those with normal body weight $(76.1 \%)(\mathrm{p}<0.05)$. It was found that orthorexic tendency did not affect some nutritional habits such as the amount of food consumed, the frequency of eating at home, the frequency of ordering food, the intakes of vitamins and minerals, the consumption of main and snack meals ( $p>0.05)$. According to the results of the regression analysis, it was determined that the changes in the consumption of milk-yogurt, poultry, and sugar increased the orthorexic score of the individuals $(\mathrm{p}<0.05)$.

Conclusion: As a result, it has been determined that individuals have a high level of orthorexic tendency during the COVID-19 pandemic process and this tendency is higher in individuals with high education levels and close to ideal body weight. Since eating disorders that develop during periods of high stress such as a pandemic can be long-term, it is important to diagnose these nutritional disorders on time and to give individuals the necessary nutritional therapy in this regard.

Keywords: Orthorexia nervosa, dietary behavior, COVID-19 pandemic

\section{GİRIŞ}

İlk kez 1997 yllında Steven Bratman tarafindan ortaya atılmış olan ortoreksiya nervoza (ON) "sağlıklı yemeye olan patolojik bir obsesyon" olarak tanımlanmaktadır (1). Ortoreksiya nervozalı bireyler genellikle sağlıklı, organik ve biyolojik olarak saf yiyeceklere patolojik bir obsesyon göstermektedir. Genetiği değiştirilmiş yiyecekler, yağ, şeker, tuz veya gıda katkı maddelerini içeren besinleri tüketmekten kaçınan ON'lı bireyler, sağlıklı yiyeceklere karşı bir saplantı sonucunda genellikle günlük rutinler oluşturmak amacıyla, yemekler arasına uzun süreler koymak veya belli yiyecekleri birlikte tüketmek gibi ritüeller oluşturmaktadırlar. Buna ek olarak gün boyunca tüketecekleri öğünlerin detaylı şekilde planlanması, alışverişin yapılması ve yiyeceklerin hazırlanması için çok fazla zaman harcamaktadırlar. Sağlıklı beslenmeye yönelik oluşturdukları kuralları uygulayamamak bu kişilerde kızgınlık, mutsuzluk, sinirli olma gibi olumsuz duygulara yol açmaktadır. Beslenme kurallarına uyabilmek için genellikle dışarıda yemek yemeği tercih etmemekte ve bu sebeple sosyalleşmeden kaçınmaktadırlar (2).
Aralık 2019'da başlayan ve birkaç ay içerisinde tüm dünyada etkili olan COVID-19 pandemisiyle mücadele etmek için birçok ülkede alınan önlemler; ekonomik sıkıntıların artması, sosyal hayatın sinırlanması, geleceğe yönelik kaygıların artması gibi sonuçları da beraberinde getirmiştir. Ayrıca bu süreçte genel hastalık riskinin artmış olması da bireylerde stres ve anksiyetenin artmasına neden olmuştur. Pandemi sürecindeki uygulamaların, kişilerin fiziksel ve mental sağlıklarına yönelik olumsuz etkileri olabileceği ve bu etkilerin yeme bozukluklarına yol açabileceği düşünülmektedir $(3,4)$. Ayrıca sağlıklı beslenmenin bağışıklık sistemini güçlendirerek koronavirüsten koruyacağı veya virüsün etkisini en aza indireceği düşüncesinin ortorektik davranışları tetikleyebileceği ortaya konmuştur (5).

Ortorektik davranışlar üzerinde diğer bir önemli etken sosyal medyadır. Sosyal medyada beslenme ve sağlık hakkında çok fazla içerik bulunmakta ve bu içerikler sağlıklı bir beslenme davranışı gelişmesine yardımcı olabildiği gibi bazen sağlıklı beslenmenin bir takıntı haline dönüşmesine de yol açabilmektedir. 
Yapılan bir çalışmada, instagram kullanımının ON eğilimini arttırdığı saptanmıştır (6). Yine bazı çalışmalarda sosyal medya kullanımının diğer yeme bozukluklarıyla da ilişkili olduğu gösterilmiştir $(7,8)$.

$\mathrm{Bu}$ çalışmanın amacl, pandemi sürecinin $\mathrm{ON}$ üzerindeki etkilerinin anlaşılabilmesi için; ortorektik eğilime sahip olan bireylerin prevalansının belirlenmesi, ortorektik bireyler ile ilişkili faktörlerin saptanması ve yeme davranışları ile ortorektik eğilim arasındaki ilişkinin değerlendirilmesidir.

\section{BIIREYLER VE YÖNTEM}

$\mathrm{Bu}$ kesitsel çalışmaya pandemi sürecinde Türkiye genelinde, çevrimiçi olarak hazırlanan anket ve ölçek sorularını yanıtlamaya gönüllü, 19 yaş ve üzeri, kronik hastalığı bulunmayan ve COVID-19 öyküsü olmayan 699 yetişkin birey (Erkek:152, Kadın:547) katılmıştır. Gebe-emziren kadınlar, psikolojik hastalığı ve yeme davranış bozukluğu olan bireyler çalışmaya dahil edilmemiştir. Oluşturulan çevrimiçi anket, TemmuzAğustos 2020 tarihleri arasında e-posta ve sosyal medya aracılığı ile duyurulmuş ve gönüllü katılımı sağlanmıştır.

Anket formu üç bölümden oluşmuştur. Birinci bölüm, bireylerin demografik bilgileri; yaş, cinsiyet, eğitim durumu, çalışma durumu ve hastalık durumu hakkındaki soruları içermektedir. İkinci bölüm, bireylerin kendi beyanlarına göre belirtilen boy uzunluğu (cm) ve vücut ağırlığı (kg) bilgileri, fiziksel aktivite durumları ile dört aylık pandemi sürecinde vücut ağırlığı ve fiziksel aktivite durumunda yaşanan değişiklikler ile beslenme bilgileri, günlük öğün sayıları, bazı yiyecek ve içeceklerin tüketim sıklıkları ve bu yiyeceklerin pandemi sürecindeki değişim durumları ve miktarlarını içermektedir. Ayrıca anket formunda besin tüketim miktarlarındaki değişim ile ilgili verilerin doğruluğunun sağlanması amacıyla sorgulanan besinlerin bir porsiyon ölçü bilgisi verilmiştir. İleri analiz için bireylerin beden kütle indeksi (BKI), vücut ağırlığı (kg)/boy uzunluğu $(\mathrm{m})^{2}$ formülü ile hesaplanmıştır. Beden kütle indeksi değerleri Dünya Sağlık Örgütü’nün (DSÖ) belirlediği aralıklara göre $18.5 \mathrm{~kg} / \mathrm{m}^{2}$ 'nin altı zayıf, $18.5-24.9 \mathrm{~kg} /$ $\mathrm{m}^{2}$ normal, $25-29.9 \mathrm{~kg} / \mathrm{m}^{2}$ fazla kilolu ve $30 \mathrm{~kg} / \mathrm{m}^{2}$ 'nin üzeri obez olarak sınıflandırılmıştır (9). Son bölümde ise pandemi sürecinde bireylerin sağlıklı beslenme takıntısını değerlendirmek için ORTO-15 ölçeği kullanılmıştır. Arusoğlu ve ark. (10) tarafından 2006 yılında Türkçe geçerlilik ve güvenilirliği yapılmış olan bu ölçek, 'her zaman, sık sık, bazen ve hiçbir zaman' cevaplarıyla değerlendirilen 15 sorudan oluşmaktadır. Ölçekte 3,4,6,7,10,12,14,15. sorular her zaman 1, sık sık 2, bazen 3 ve her zaman 4 puan olarak puanlanmakta iken, 2,5,8,9. sorular tam tersi olarak puanlanmakta, 1 . ve 13. sorular ise her zaman 2, sık sık 4, bazen 3 ve hiçbir zaman 1 puan olarak puanlanmaktadır. Ölçeğin değerlendirilmesinde 40 kesim noktası olup, puan artışı ON riskinin azaldığını göstermektedir.

Bu çalışma için, 2020-05-19T13_15_24 nolu karar ile Sağlık Bakanlığı Bilimsel Araştırma Platformu'ndan onay ve 17/06/2020 tarih 34-35 nolu karar ile Toros Üniversitesi Bilimsel Araştırma Yayın Etik Kurulundan etik kurul izni alınmıştır. Ayrıca çalışmaya katılan bireylerden çalışma öncesi onam alınmıştır.

\section{Verilerin İstatistiksel Değerlendirilmesi}

Araştırma verilerinin analizinde, bağımsız örneklemler t-testi ve ki-kare testleri kullanılmıştır. İki bağımsız grup karşılaştırmasında normallik varsayımı için Kolmogorov-Smirnov testi ve varyans homojenlik varsayımı için de Levene testi sonuçları incelenmiştir. Analiz sonucunda normallik ve varyans homojenlik varsayımı sağlandığı bulgusu göz önüne alınarak bağımsız iki grup karşılaştırmalarında bağımsız örneklemler t-testi uygulanmıştır. Ki-kare testlerinde çapraz tablo hücrelerinin beklenen değerleri göz önüne alınarak Yates düzeltmesi veya Fisher testi uygulanmıştır. Nicel veriler arası ilişkileri incelemek için Pearson korelasyon analizi; nicel bağımlı skorlar üzerindeki etkileri modellemek için lineer normal regresyon analizi kullanılmıştır. Analizler IBM SPSS 22 programı ile gerçekleştirilmiştir. Çalışmada $\mathrm{p}<0.05$ değeri istatistiksel olarak anlamlı kabul edilmiştir. 


\section{BULGULAR}

Çalışmaya \%21.7’si erkek, \%78.3'ü kadın olmak üzere toplam 699 birey dahil edilmiştir. Katılımcıların yaş ortalaması $28.7 \pm 10.5$ yll, BKI ortalaması $23.4 \pm 4.4 \mathrm{~kg} /$ $\mathrm{m}^{2}$ ve ORTO-15 skor ortalaması 37.4 \pm 3.9 'dir. Bireylerin $\% 68.2$ 'sinin ON eğilimi olduğu ve ortorektik eğilime sahip olma durumları ile cinsiyet, çalışma durumu, eğitim durumları, vücut ağırlğ̆ değişimi ve BKİ düzeyleri arasında istatistiksel olarak anlamlı bir ilişki olduğu bulunmuştur $(\mathrm{p}<0.05)$. Tablo 1'deki bulgular incelendiğinde ise; kadın bireylerin \%66.4'ünün, erkek bireylerin \%75.0'inin ve çalışan grubun \%76.6'sının, çalışmayan grubun \%63.7’sinin ortorektik eğilime sahip olduğu gözlenmekte iken eğitim seviyesi lise ve altı olan grubun \%61.5'inin, üniversite olan grubun \%66.7’sinin, lisansüstü grubun \%79.5'i ortorektik eğilime sahip olduğu görülmektedir. Vücut ağırlı̆̆ı artış1 1-5 kg arası olan bireylerin \%71.7'si, 5-10 kg arası olan bireylerin \%68.2'si, 10-15 kg arası olan bireylerin \%33.3’ü ortorektik eğilime sahiptir. Beden kütle indeksine göre zaylf olan bireylerin \%57.9'unun, normal vücut ağırlı̆ıında olan bireylerin \%76.1'inin, fazla kilolu olan bireylerin \%67.9'unun, obez olan bireylerin ise \%60.0'ının ortorektik eğilime sahip olduğu bulunmuştur.

Tablo 2'de bireylerin ortorektik eğilime sahip olma durumları ile öğün sayısı değişimleri arasında istatistiksel olarak anlamlı bir ilişki olduğu görülmektedir $(\mathrm{p}<0.05)$. Ortorektik eğilime sahip olan bireylerin \%20.5'inin öğün sayısının azaldığı, \%38.4'ünin arttığı, \%41.1'inin ise değişmediği; ortorektik eğilime sahip olmayan bireylerin öğün sayısındaki değişikliğin ise sırasıyla; \%30.6, \%37.4 ve \%32.0 olduğu saptanmıştır.

Tablo 3'te ortorektik skor puanı bağımlı değişken alınarak bireylerin besin tüketim değişimlerinin etkilerini gözlemlemek için elde edilen regresyon analizi sonuçları gösterilmektedir. Regresyon analizi sonuçlarına göre süt-yoğurt, tavuk ve şeker tüketiminde yaşanan değişimlerin bireylerin

Tablo 1. Bireylerin genel özelliklerinin ortorektik eğilime sahip olma durumlarına göre dağılımları

\begin{tabular}{|c|c|c|c|c|c|}
\hline \multirow[t]{2}{*}{ Genel özellikler } & \multicolumn{2}{|c|}{$\begin{array}{l}\text { Ortorektik eğilimi olanlar } \\
\text { (n:477) }\end{array}$} & \multicolumn{2}{|c|}{$\begin{array}{l}\text { Ortorektik eğilimi } \\
\text { olmayanlar (n:222) }\end{array}$} & \multirow[t]{2}{*}{$\mathbf{p}$} \\
\hline & $\mathbf{n}$ & $\%$ & $\mathbf{n}$ & $\%$ & \\
\hline \multicolumn{6}{|l|}{ Cinsiyet } \\
\hline Erkek & 114 & 75.0 & 38 & 25.0 & \multirow{2}{*}{0.043} \\
\hline Kadın & 363 & 66.4 & 184 & 33.6 & \\
\hline \multicolumn{6}{|l|}{ Çalışma Durumu } \\
\hline Evet & 187 & 76.6 & 57 & 23.4 & \multirow{2}{*}{$<0.001$} \\
\hline Hayır & 290 & 63.7 & 165 & 36.3 & \\
\hline \multicolumn{6}{|l|}{ Eğitim Durumu } \\
\hline Lise ve altı & 40 & 61.5 & 25 & 38.5 & \multirow{3}{*}{0.015} \\
\hline Üniversite & 348 & 66.7 & 174 & 33.3 & \\
\hline Lisansüstü & 89 & 79.5 & 23 & 20.5 & \\
\hline \multicolumn{6}{|l|}{$B K I\left(k g / m^{2}\right)$} \\
\hline Zaylf (<18.5) & 33 & 57.9 & 24 & 42.1 & \multirow{4}{*}{0.020} \\
\hline Normal (18.5-24.9) & 118 & 76.1 & 38 & 23.9 & \\
\hline Fazla kilolu ( $\geq 25.0-29.9$ ) & 293 & 67.9 & 138 & 32.1 & \\
\hline Obez $(\geq 30.0)$ & 33 & 60.0 & 22 & 40.0 & \\
\hline \multicolumn{6}{|c|}{4 Ayda Vücut Ağırlığı Artışı (kg) } \\
\hline $1-5$ & 241 & 71.7 & 95 & 28.3 & \multirow{3}{*}{0.047} \\
\hline $5-10$ & 58 & 68.2 & 27 & 31.7 & \\
\hline $10-15$ & 3 & 33.3 & 6 & 66.7 & \\
\hline
\end{tabular}


Tablo 2. Bireylerin karantina sürecindeki beslenme alışkanlıklarının ortorektik eğilime sahip olma durumlarına göre değerlendirilmesi

\begin{tabular}{|c|c|c|c|c|c|}
\hline \multirow[t]{2}{*}{ Beslenme alışkanlıkları } & \multicolumn{2}{|c|}{$\begin{array}{l}\text { Ortorektik eğilimi } \\
\text { olanlar (n:477) }\end{array}$} & \multicolumn{2}{|c|}{$\begin{array}{c}\text { Ortorektik eğilimi } \\
\text { olmayanlar (n:222) }\end{array}$} & \multirow{2}{*}{$\mathbf{p}$} \\
\hline & $\mathbf{n}$ & $\%$ & $\mathbf{n}$ & $\%$ & \\
\hline \multicolumn{6}{|l|}{ öğün sayısı } \\
\hline Azaldı & 98 & 20.5 & 68 & 30.6 & \multirow{3}{*}{0.007} \\
\hline Arttı & 183 & 38.4 & 83 & 37.4 & \\
\hline Değişmedi & 196 & 41.1 & 71 & 32.0 & \\
\hline \multicolumn{6}{|l|}{ Yiyecek miktarı } \\
\hline Azaldı & 85 & 17.8 & 41 & 18.5 & \multirow{3}{*}{0.925} \\
\hline Arttı & 259 & 54.3 & 117 & 52.7 & \\
\hline Değişmedi & 133 & 27.9 & 64 & 28.8 & \\
\hline \multicolumn{6}{|l|}{ Evde yemek pişirme sıklığı } \\
\hline Azaldı & 22 & 4.6 & 8 & 3.6 & \multirow{3}{*}{0.726} \\
\hline Arttl & 336 & 70.5 & 162 & 73.0 & \\
\hline Değişmedi & 119 & 24.9 & 52 & 23.4 & \\
\hline \multicolumn{6}{|l|}{ Yemek sipariş sıklığı } \\
\hline Azaldl & 372 & 78.0 & 159 & 71.6 & \multirow{3}{*}{0.159} \\
\hline Arttı & 29 & 6.1 & 15 & 6.8 & \\
\hline Değişmedi & 76 & 15.9 & 48 & 21.6 & \\
\hline \multicolumn{6}{|c|}{ Karantina öncesi vitamin-mineral kullanım durumu } \\
\hline Evet & 73 & 15.3 & 34 & 15.3 & \multirow{3}{*}{0.797} \\
\hline Hayır & 372 & 78.0 & 170 & 76.6 & \\
\hline Bazen & 32 & 6.7 & 18 & 8.1 & \\
\hline \multicolumn{6}{|c|}{ Karantina süreci vitamin-mineral kullanım durumu } \\
\hline Evet & 97 & 20.3 & 39 & 17.6 & \multirow{3}{*}{0.691} \\
\hline Hayır & 353 & 74.0 & 170 & 76.6 & \\
\hline Bazen & 27 & 5.7 & 13 & 5.9 & \\
\hline \multicolumn{6}{|l|}{ Ana öğün tüketim durumu } \\
\hline $1-2$ & 299 & 62.7 & 153 & 68.9 & \multirow{2}{*}{0.108} \\
\hline 3 & 178 & 37.3 & 69 & 31.1 & \\
\hline \multicolumn{6}{|l|}{ Ara öğün tüketim durumu } \\
\hline 1 & 114 & 30.2 & 52 & 28.7 & \multirow{2}{*}{0.715} \\
\hline $2-3$ & 263 & 69.8 & 129 & 71.3 & \\
\hline
\end{tabular}

ortorektik skor puanı üzerinde istatistiksel olarak anlamlı etkisinin olduğu belirlenmiştir $(\mathrm{p}<0.05)$. Regresyon katsayları incelendiğinde ise süt-yoğurt tüketimindeki artışın ortorektik skor puanını 1.932 kat $(p<0.001)$, tavuk tüketimindeki artışın ise 1.003 kat $(p=0.036)$ azalttığı saptanırken; şeker tüketimindeki artışın ise ortorektik skor puanını 1.166 kat $(\mathrm{p}<0.001)$ artırdığı saptanmıştır.

\section{TARTIŞMA}

Sağlıklı beslenme takıntısı olarak tanımlanan ON'nın yeme bozukluğu konusunda resmi bir tanı kategorisi olarak sınıflandırılması halen tartışma konusu olmasına rağmen; mükemmeliyetçilik, beslenme konusundaki bilişsel sabitlenme, yüksek kaygı ve kontrol ihtiyacı yönünden diğer yeme bozuklukları ile benzerlik göstermektedir (11). 
Tablo 3. Bireylerin besin tüketim değişimlerinin ortorektik skor puanı üzerindeki etkilerini değerlendiren regresyon analizi sonuçları

\begin{tabular}{|c|c|c|c|c|c|c|}
\hline Değişken & Katsayı & $\beta$ & SH & $\mathbf{T}$ & $\mathbf{p}$ & $\mathbf{R}^{2} \%$ \\
\hline \multirow{2}{*}{ Süt-yoğurt } & Sabit terim & 39.104 & 0.542 & 72.139 & $\mathrm{p}<0.001$ & \multirow{2}{*}{3.325} \\
\hline & Arttı [Ref=Azaldl $]$ & -1.932 & 0.589 & -3.281 & $<0.001$ & \\
\hline \multirow{2}{*}{ Peynir } & Sabit terim & 37.317 & 0.585 & 63.759 & $\mathrm{p}<0.001$ & \multirow{2}{*}{0.031} \\
\hline & Arttı [Ref=Azaldı] & 0.191 & 0.630 & 0.303 & 0.762 & \\
\hline \multirow{2}{*}{ Kırmızı et } & Sabit terim & 37.643 & 0.419 & 89.801 & $\mathrm{p}<0.001$ & \multirow{2}{*}{0.042} \\
\hline & Arttı [Ref=Azaldı] & -0.176 & 0.491 & -0.359 & 0.720 & \\
\hline \multirow{2}{*}{ Tavuk } & Sabit terim & 38.167 & 0.391 & 97.516 & $\mathrm{p}<0.001$ & \multirow{2}{*}{1.483} \\
\hline & Arttı [Ref=Azaldı] & -1.003 & 0.475 & -2.111 & 0.036 & \\
\hline \multirow{2}{*}{ Balık } & Sabit terim & 37.255 & 0.270 & 138.021 & $\mathrm{p}<0.001$ & \multirow{2}{*}{0.001} \\
\hline & Arttı [Ref=Azaldı] & -0.019 & 0.486 & -0.039 & 0.969 & \\
\hline \multirow{2}{*}{ Ekmek } & Sabit terim & 37.273 & 0.335 & 111.116 & $\mathrm{p}<0.001$ & \multirow{2}{*}{0.181} \\
\hline & Arttı [Ref=Azaldı] & 0.344 & 0.430 & 0.801 & 0.424 & \\
\hline \multirow{2}{*}{ Unlu mamuller } & Sabit terim & 37.259 & 0.367 & 101.582 & $\mathrm{p}<0.001$ & \multirow{2}{*}{0.118} \\
\hline & Arttı [Ref=Azaldı] & 0.298 & 0.436 & 0.684 & 0.494 & \\
\hline \multirow{2}{*}{ Pilav-makarna } & Sabit terim & 37.140 & 0.378 & 98.150 & $\mathrm{p}<0.001$ & \multirow{2}{*}{0.070} \\
\hline & Arttı [Ref=Azaldı] & 0.221 & 0.460 & 0.481 & 0.631 & \\
\hline \multirow{2}{*}{ Bisküvi-kraker } & Sabit terim & 37.339 & 0.291 & 128.376 & $\mathrm{p}<0.001$ & \multirow{2}{*}{0.044} \\
\hline & Arttı [Ref=Azaldı] & 0.161 & 0.401 & 0.402 & 0.688 & \\
\hline \multirow{2}{*}{ Sebze } & Sabit terim & 37.720 & 0.547 & 69.020 & $\mathrm{p}<0.001$ & \multirow{2}{*}{0.056} \\
\hline & Arttı [Ref=Azaldı] & -0.265 & 0.589 & -0.450 & 0.653 & \\
\hline \multirow{2}{*}{ Taze meyve } & Sabit terim & 38.040 & 0.450 & 84.490 & $\mathrm{p}<0.001$ & \multirow{2}{*}{0.304} \\
\hline & Arttı [Ref=Azaldı $]$ & -0.540 & 0.504 & -1.071 & 0.285 & \\
\hline \multirow{2}{*}{ Kuru meyve } & Sabit terim & 37.669 & 0.327 & 115.269 & $\mathrm{p}<0.001$ & \multirow{2}{*}{0.492} \\
\hline & Arttı [Ref=Azaldı] & -0.537 & 0.441 & -1.217 & 0.224 & \\
\hline \multirow{2}{*}{ Kuru yemiş } & Sabit terim & 38.099 & 0.461 & 82.725 & $\mathrm{p}<0.001$ & \multirow{2}{*}{1.279} \\
\hline & Arttı [Ref=Azaldı $]$ & -1.026 & 0.529 & -1.938 & 0.054 & \\
\hline \multirow{2}{*}{ Sivıyă̆-tereyăg } & Sabit terim & 36.750 & 0.443 & 83.039 & $\mathrm{p}<0.001$ & \multirow{2}{*}{0.312} \\
\hline & Arttı [Ref=Azaldı] & 0.484 & 0.518 & 0.934 & 0.351 & \\
\hline \multirow{2}{*}{ Şeker } & Sabit terim & 36.801 & 0.315 & 116.804 & $\mathrm{p}<0.001$ & \multirow{2}{*}{2.230} \\
\hline & Arttı [Ref=Azaldı] & 1.166 & 0.446 & 2.616 & $<0.001$ & \\
\hline
\end{tabular}

B: Beta katsayıs, SH: Standart hata, $R^{2}$ : Belirtme katsayıs

COVID-19 pandemi sürecindeki ON yatkınlı̆̆ını ve ilişkili olduğu etmenleri belirlemek amacıyla yapılan bu çalışmada, çalışmaya katılan bireylerin \%68.2'sinin ON eğilimine sahip olduğu bulunmuştur. Macaristan'da yapılan bir çalışmada, çalışmaya katılan bireylerin \%56.9'unun ON’ya eğilimli olduğu (12), ORTO-15 ölçeği kullanılarak yapılan başka bir çalışmada ise katılımcıların \%54.6’sının ON kriterlerini karşıladığı saptanmıştır (13). Bu çalışmada olduğu gibi çoğu araştırmacı tarafindan da kullanılan ORTO-15 ölçeği altın standart olarak gösterilmesine rağmen, patolojik kısıtlaması olan bireyleri belirlemekten ziyade sağlıklı beslenmeyi belirlemek için kullanıldığı görülmektedir (14). Bu sınırlamanın mevcut çalışmadaki yüksek ON eğilim oranını da açılayabileceği düşünülmektedir. Ayrıca COVID-19 pandemi sürecinde besin kalitesi ve bu besinlerin sağlığa ve enfeksiyona olan olası etkileri konusunda görsel ve yazılı medyada yer alan birçok bilginin yayıncı tarafından yanlış aksettirilmesi ve 
tüketici tarafından yanlış yorumlanmasının sağlıklı beslenme takıntısına zemin hazırlayabileceği ve bu çalışmadaki yüksek ON oranının bu nedenlerden kaynaklanabileceği şeklinde yorumlanmaktadır.

Ortoreksiya nervoza etiyolojisinde cinsiyet ve eğitim durumu gibi bazı demografik faktörlerin de etkili olabileceği vurgulanmaktadır (10). Cinsiyetin ortorektik eğilim üzerindeki etkisinin ORTO-15 ölçeği ile değerlendirildiği çalışmalarda erkek bireylerin ortorektik eğilimlerinin kadın bireylere göre daha fazla olduğu $(14,15)$ savunulurken, diğer ölçeklerle yapılan çalışmalar da ise tersi $(10,16)$ rapor edilmiştir. Literatürdeki bu farklılıklar ON'nın kesin bir tanısı olmamasından ve eğilimin belirlenmesinde farklı ölçekler kullanılmasından kaynaklanmaktadır. ORTO-15 ölçeğinin kullanıldığı bu çalışmada da erkek bireylerin kadın bireylere göre daha fazla ortorektik eğilime sahip olduğu bulunmuştur ( $\mathrm{p}<0.05$, Tablo 1$)$.

Literatürde demografik faktörlerden eğitim durumu ile ON eğilimi arasındaki ilişki de çelişkilidir. Almanya'da üniversite öğrencileri ile yapılan bir çalışmada sınıf sayısı arttıkça sağlıklı besinlere yönelimin daha fazla olduğu görülmüştür (17). Ülkemizde yapılan bir çalışmada ise lisansüstü eğitim düzeyine sahip bireylerin diğer eğitim düzeylerine sahip bireylere göre daha düşük ortorektik eğilime sahip olduğu bulunmuştur (10). Bunun aksine ON eğiliminin eğitimden bağımsız olduğunu gösteren çalışmalarda mevcuttur $(13,18,19)$. Bu çalışmada ise en fazla ortorektik eğilime sahip olma oranının lisansüstü eğitimi olan bireylerde olduğu görülmektedir $(\mathrm{p}<0.05$, Tablo 1). Bu sonucun artan bilgi seviyesi ile besinlerin kalitesine duyulan güven arasındaki dengesizlikten kaynaklanabileceği düşünülmektedir.

Beden kütle indeksi, bireyin ortorektik eğilimini etkileyen önemli faktörlerdendir (20-22). Literatürde bu konu ile ilgili yapılan çalışmalar farklılık göstermektedir. Ülkemizde yapılan bir çalışmada zayıf bireylerin hem normal vücut ağırlığına sahip olan hem de obez olan bireylere göre daha az ON eğilimine sahip olduğu belirlenirken (22), bir diğer çalışmada ise BKI değeri arttıkça ON riskinin yükseldiği belirlenmiştir (23). Bu çalışmaların aksine yapılan başka bir çalışmada ise ortorektik eğilim ile BKI değerleri arasında anlamlı bir ilişki bulunmamıştır (10). Yapılan bu çalışmada, bireylerin vücut ağırlığı artışı ve BKİ grupları ile ortorektik eğilime sahip olma durumu arasında istatistiksel olarak anlamlı bir ilişki olduğu saptanmıştır $(p<0.05)$. Ortorektik eğilimin vücut ağırlık artışı en yüksek (10-15 kg) olan bireylerde en düşük, normal BKİ değerine sahip olan bireylerde ise en yüksek olduğu belirlenmiştir (sırasıyla \%66.7, $\% 76.1 ; \mathrm{p}<0.05$, Tablo 1). Çıkan bu sonuç, normal vücut ağırlığına sahip bireylerin ideal vücut ağırlığını korumak için gösterdikleri çabalardan kaynaklı olabileceği şeklinde yorumlanmaktadır.

Sağlıklı beslenme konusunda katı kurallara sahip olan ortorektik bireyler tükettikleri besinlerin sınırlı olmasının yanı sıra besinlerin hazırlanma yöntemleri ve hazırlama aşamasında kullanılan malzemeler konusundaki hassasiyetleri nedeniyle ev dışından yemek yememeye ve yemeklerini kendileri yapmaya dikkat etmektedirler $(24,25)$. Ancak, bu çalışmada yemek sipariş sıklığı ve evde yemek pişirme sıklığı ile ON eğilimi arasında anlamlı bir ilişki bulunmamış olup her iki grupta da evde yemek pişirme sıklığının arttığı, sipariş verme sıklığının ise azaldığı belirlenmiştir ( $>0.05$, Tablo 2). Bu sonucun nedeni olarak pandemi sürecinde ortaya çıkan virüs bulaşma endişesinin yanı sıra bireylerin kapanma nedeni ile yemek yapmaya daha fazla vakit ayırabilmeleri olduğu düşünülmektedir. Ortorektik bireylerin, tüketilen besinlerin miktarından çok kökeni, üretim süreçleri, paketleme ve sağlık üzerine olası etkileri konusuna daha çok zaman harcaması öğün sıklıklarının azalmasına yol açmaktadır (26). Bu konuda yapılan bir çalışmada, ortorektik bireylerin vücut imajındaki memnuniyetsizliğin düzensiz yeme ve öğün sıklığındaki azalma ile ilişkili olduğu gösterilmiştir (27). Bunların aksine Plictha et al. (28) çalışmasına uyumlu olarak bu çalışmada da bireylerin ortorektik eğilime sahip olma durumları ile öğün sayısı değişimleri arasında istatistiksel olarak anlamlı bir ilişki olduğu ancak ON eğilimine sahip olan grubun büyük çoğunluğunun öğün sılklğının 
değişmediği belirlenmiştir $(\mathrm{p}<0.05$, Tablo 2). $\mathrm{Bu}$ durumu ON eğilimi olan bireylerin besin tüketme sıklığının dışında spesifik yeme alışkanlıklarına sahip olmaları ile ilişkilendirmek mümkündür.

Ortoreksiya nervozanın temelinde sağlıksız beslenmeye bağlı hastalanma korkusu vardır. Bu yüzden ortorektik bireyler başlangıçta sağlıklı bir diyet ile optimal sağlığı elde etme amacında iken, diyet zamanla hayatlarının odak noktası haline gelmektedir (29). Pandemi sırasında sağlıklı beslenme ile ilgili artan endişeler bu durumu daha da arttırmaktadır (30). Rodgers et al. (5) yaptıkları bir çalışmada, COVID-19 pandemisi sürecinde sağllklı beslenme ile ilgili endişelerin artması nedeniyle ortorektik semptomların artabileceğini vurgulamışlardır. Bu bağlamda ortorektik bireyler fazla miktarda tuz, şeker içeren sağlıksız yiyecekleri tüketmekten kaçınmakta, sadece çiğ sebze ve belirli besinleri tüketme eğiliminde olmaktadır (31-34). Polonya'da üniversite öğrencileri ile yapılan çalışmalarda şekerli ürünleri fazla tüketen bireylerin daha az ortorektik eğilime sahip olduğu bulunmuştur $(28,29)$. Bu çalışmaya uyumlu olarak mevcut çalışmamızda da şeker tüketimi arttıkça bireylerin ortorektik eğilimlerinin azaldığı saptanmıştır ( $p<0.05$, Tablo 3$)$.

Ortoreksiya nervoza prevalansı çeşitli hayvansal besinlerin kısitlanmasina dayanan vejetaryen, vegan ve çiğ besin diyeti uygulayan bireyler arasında daha yüksektir $(35,36)$. Yapılan bazı çalışmalarda, vejetaryen ya da vegan diyetlerin belirli yiyeceklerden ve yeme durumlarından kaçınmanın sosyal olarak kabul edilebilir bir yolu olabileceği vurgulanarak ON eğilimi ile ilişkilendirilmektedir (37,38). Bu çalışmaların aksine İtalya'da yapılan bir çalışmada ise hayvansal besinlerin kullanımının kısıtlanması ve hiç tüketilmemesinin ON ile bir ilişkisinin olmadiğ 1 saptanmıştır (39). Bu çalışmada da süt, yoğurt ve tavuk tüketimi arttıkça bireylerin ortorektik eğilimlerinin arttığı belirlenmiştir $(p<0.05$, Tablo 3). Ortorektik bireylerin hayvansal besinleri tercih sebepleri bu besinlerin daha zengin protein kalitesine sahip olmaları ile ilişkilendirilmektedir (40). Ayrıca, pandemi sürecinde bağışıklığı güçlendirme kaygısıyla sağlıklı beslenmeye olan ilginin artması da bu sonucu desteklemektedir.

Çalışmada çevrimiçi bir anketin kullanılması, ülkenin her yerinden verilerin toplanmasını sağlayarak, güçlü bir yön oluşturmasının yanı sıra çalışmanın kabul edilmesi gereken bazı kısıtlılıkları da vardır. Öncelikle kesitsel bir çalışma olduğu için ilişkilerin nedenselliği değerlendirilememiştir. Çalışmada ortorektik bireylere tanı konulurken; klinik tanı görüşmesi yoluyla değil, bir puanlama aracı olarak kullanılan ORTO-15 ölçeği kullanılmıştır, bu nedenle yanıtların doğruluğu teyit edilememiştir. Ayrıca çalışmaya katılan kadın bireyler sayısal olarak erkeklerden daha fazladır ve bireylerin COVID-19 pandemisi öncesine ait bilgileri alınmadığı için dönemler arasında kıyaslama yapılamamıştır.

Sonuç olarak, COVID-19 pandemi sürecinde bireylerin yüksek oranda ortorektik eğilime sahip oldukları ve bu eğilimin yüksek eğitim seviyesine sahip, ideal vücut ağırlığına yakın olan bireylerde daha fazla olduğu belirlenmiştir. Pandemi sürecinde bireyler COVID-19 hastalığına neden olan koronavirüsün yanı sıra hem görsel hem de yazılı medyada yer alan bilgi kirliliği sebebiyle artan endişeye maruz kalmıştır. $\mathrm{Bu}$ endişeye bağlı beslenme alışkanlığında yapılan hatalı ya da takıntılı değişikliklerin yeme bozukluklarına neden olabileceği düşünülmektedir. $\mathrm{Bu}$ nedenle özellikle pandemi gibi hassas süreçlerde topluma her konuda olduğu gibi beslenme konusunda da doğru bilgilerin verilmesine özen gösterilmesi ve olumsuz bir durumda zamanında müdahale edilmesi çok önemlidir. Ayrıca ilerleyen zamanlarda yapılacak olan çalışmalarda eşit sayıda kadın ve erkek bireyin katıldığı, tanı değerlendirmesinin klinik olarak yapıldığı ve COVID-19 enfeksiyonu geçirmiş olan bireylerin de dahil edildiği çalışmaların yapılması daha anlamlı sonuçlar elde edilmesini sağlayacaktır..

Yazarlık katkısı - Author contributions: Çalışmanın tasarımı: ÖÖA, EA, MVY; Çalışma verilerinin elde edilmesi: ÖÖA, EA, MVY; Verilerin analiz edilmesi: ÖÖA, EA, MVY; Makale taslağının oluşturulması: ÖÖA, MVY; İçerik için eleştirel gözden geçirme: ÖÖA, EA, MVY; Yayınlanacak 
versiyonun son onayl: ÖÖA, EA, MVY. - Study design: ÖÖA, EA, MVY; Data collection: ÖÖA, EA, MVY; Data analysis: ÖÖA, EA, MVY; Draft preparation: ÖÖA, MVY; Critical review for content: ÖÖA, EA, MVY; Final approval of the version to be published: ÖÖA, EA, MVY.

Etik Kurul Onayı - Ethics approval: Bu çalışma için, 202005-19T13_15_24 nolu karar ile Sağllk Bakanllğı Bilimsel Araştırma Platformu'ndan onay ve 17/06/2020 34-35 nolu karar ile Toros Üniversitesi Bilimsel Araştırma Yayın Etik Kurulundan etik kurul izni alınmıştır. - For this study, approval from the Ministry of Health Scientific Research Platform with the decision numbered 2020-05-19T13_15_24 and ethics committee approval from the Scientific Research Publication Ethics Committee of Toros University with the decision numbered 34-35 on 17/06/2020.

Çıkar çatışması - Conflict of interest: Yazarlar çıkar çatışması olmadığını beyan ederler. - The authors declare that they have no conflict of interest.

\section{KAYNAKLAR}

1. Opitz M-C, Newman E, Mellado ASAV, Robertson M, Sharpe $\mathrm{H}$. The psychometric properties of orthorexia nervosa assessment scales: A systematic review and reliability generalization. Appetite. 2020:104797.

2. Rogowska AM, Kwaśnicka A, Ochnik D. Development and validation of the test of orthorexia nervosa (TON17). J Clinl Med. 2021;10(8):1637.

3. Castellini G, Cassioli E, Rossi E, Innocenti M, Gironi V, Sanfilippo G, et al. The impact of COVID-19 epidemic on eating disorders: A longitudinal observation of pre versus post psychopathological features in a sample of patients with eating disorders and a group of healthy controls. Int J Eat Disord. 2020;53(11):1855-62.

4. Mukhtar S. Psychological health during the coronavirus disease 2019 pandemic outbreak. Int J Soc Psychiatry. 2020;66(5):512-6.

5. Rodgers RF, Lombardo C, Cerolini S, Franko DL, Omori M, Fuller-Tyszkiewicz M, et al. The impact of the COVID-19 pandemic on eating disorder risk and symptoms. Int J Eat Disord. 2020;53(7):1166-70.

6. Turner PG, Lefevre CE. Instagram use is linked to increased symptoms of orthorexia nervosa. Eat Weight Disord. 2017;22(2):277-84.

7. Aparicio-Martinez P, Perea-Moreno AJ, MartinezJimenez MP, Redel-Macías MD, Pagliari C, VaqueroAbellan M. Social media, thin-ideal, body dissatisfaction and disordered eating attitudes: An exploratory analysis. Int J Environ Res Public Health. 2019;16(21):4177.
8. Lonergan AR, Bussey K, Fardouly J, Griffiths S, Murray SB, Hay P, et al. Protect me from my selfie: Examining the association between photo-based social media behaviors and self-reported eating disorders in adolescence. Int J Eat Disord. 2020;53(5):485-96.

9. Weir CB, Jan A. BMI Classification Percentile And Cut Off Points. [Updated 2021 Jun 29]. In: StatPearls [Internet]. Treasure Island (FL): StatPearls Publishing; 2021 Jan-. Available from: https://www.ncbi.nlm.nih.gov/books/ NBK541070/ Accessed September 10, 2021.

10. Arusoğlu G, Kabakçi E, Köksal G, Merdol T. Ortoreksiya nervoza ve orto-11'in Türkçeye uyarlama çalışması. Türk Psikiyatri Derg. 2008;19(3):283-91.

11. Mathieu J. What is pregorexia? J Am Diet Assoc. 2009;109(6):976-9.

12. Varga M MG. Eating and body image related problems in orthorexia nervosa. The 17th International Conference on Eating Disorders; Congress Centrum Alpbach, Tirol, Austri: Abstract book; October 22-24, 2009.

13. Aksoydan E, Camci N. Prevalence of orthorexia nervosa among Turkish performance artists. Eat Weight Disord. 2009;14(1):33-7.

14. Donini LM, Marsili D, Graziani MP, Imbriale M, Cannella C. Orthorexia nervosa: validation of a diagnosis questionnaire. Eat Weight Disord. 2005;10(2):e28-32.

15. Arusoğlu G. Beslenme ve Diyetetik Bölümü erkek öğrencilerinde ortoreksiya nervoza eğiliminin belirlenmesi. ASOS Journal. 2018;6(86):56-71.

16. Okumuşoğlu S. Diyet yapan kadınlarda beden algısı, benlik saygısı, yaş ve vücut kitle indeksi ilişkisinin araştırılması. Ulakbilge Sosyal Bilimler Dergisi. 2017;5(13):1171-81.

17. KinzlJF, Hauer K, Traweger C, Kiefer I. Orthorexia nervosa in dieticians. Psychotherapy and Psychosomatics. 2006;75(6):395-6.

18. Bağci Bosi AT, Camur D, Güler C. Prevalence of orthorexia nervosa in resident medical doctors in the Faculty of Medicine (Ankara, Turkey). Appetite. 2007;49(3):661-6.

19. Fidan T, Ertekin V, Işikay S, Kirpinar I. Prevalence of orthorexia among medical students in Erzurum, Turkey. Compr Psychiatry. 2010;51(1):49-54.

20. Bellodi L, Cavallini MC, Bertelli S, Chiapparino D, Riboldi C, Smeraldi E. Morbidity risk for obsessive-compulsive spectrum disorders in first-degree relatives of patients with eating disorders. Am J Psychiatry. 2001;158(4):5639.

21. Korinth A, Schiess S, Westenhoefer J. Eating behaviour and eating disorders in students of nutrition sciences. Public Health Nutr. 2010;13(1):32-7.

22. Gezer C, Kabaran S. Beslenme ve Diyetetik Bölümü kız öğrencileri arasında görülen ortoreksiya nervosa riski. S.D.Ü Sağlık Bilimleri Derg. 2013;4(1):14-22. 
23. Sanlier N, Yabanci N, Alyakut O. An evaluation of eating disorders among a group of Turkish university students. Appetite. 2008;51(3):641-5.

24. Bratman S KD. Health food junkies: Overcoming the obsession with healthful eating. New York: Broadway Books; 2000.

25. Kratina K. Orthorexia Nervosa. National Eating Disorders Association (NEDA) 2012:1-2. https:// www.nationaleatingdisorders.org/sites/default/files/ ResourceHandouts/Orthorexia.pdf Accessed August $10,2021$.

26. Brytek-Matera A, Rogoza R, Gramaglia C, Zeppegno P. Predictors of orthorexic behaviours in patients with eating disorders: A preliminary study. BMC psychiatry. 2015;15:252.

27. Eriksson L, Baigi A, Marklund B, Lindgren EC. Social physique anxiety and sociocultural attitudes toward appearance impact on orthorexia test in fitness participants. Scand J Med Sci Sports. 2008;18(3):389-94.

28. Plichta M, Jezewska-Zychowicz M. Orthorexic tendency and eating disorders symptoms in polish students: Examining differences in eating behaviors. Nutrients. 2020;12(1):218.

29. Plichta M, Jezewska-Zychowicz M, Gębski J. Orthorexic tendency in Polish students: Exploring association with dietary patterns, body satisfaction and weight. Nutrients. 2019;11(1):100.

30. Al-Musharaf S. Prevalence and predictors of emotional eating among healthy young Saudi women during the covid-19 pandemic. Nutrients. 2020;12(10):2923.

31. Kazmierczak N, Lukasiewicz K, Niedzielski A, editors. The outlook, behavior and eating habits occurring in the course of orthorexia nervosa. Piel Zdr Publ. 2017;7(2):125-33.

32. Plichta M, Jezewska-Zychowicz M. Eating behaviors, attitudes toward health and eating, and symptoms of orthorexia nervosa among students. Appetite. 2019;137:114-23.

33. Bartrina JA. Orthorexia or when a healthy diet becomes an obsession. Arch Latinoam Nutr. 2007;57(4):313-5.

34. Granbois C. What are the needs, factors, behaviors, and complications associated with type 1 diabetic adolescent females with disordered eating? Retrieved from Sophia, the St. Catherine University repository Available from: https://sophia.stkate.edu/ma_nursing/4 Accessed August, 1, 2021.

35. Dell’Osso L, Abelli M, Carpita B, Pini S, Castellini G, Carmassi C, et al. Historical evolution of the concept of anorexia nervosa and relationships with orthorexia nervosa, autism, and obsessive-compulsive spectrum. Neuropsychiatr Dis Treat. 2016;12:1651-60.

36. Catalina Zamora ML, Bote Bonaechea B, García Sánchez F, Ríos Rial B. Orthorexia nervosa. A new eating behavior disorder?. Actas Esp Psiquiatr. 2005;33(1):66-8.

37. Barthels F, Meyer F, Pietrowsky R. Orthorexic and restrained eating behaviour in vegans, vegetarians, and individuals on a diet. Eat Weight Disord. 2018;23(2):15966.

38. Chard CA, Hilzendegen C, Barthels F, Stroebele-Benschop N. Psychometric evaluation of the English version of the Düsseldorf Orthorexie Scale (DOS) and the prevalence of orthorexia nervosa among a U.S. student sample. Eat Weight Disord. 2019;24(2):275-81.

39. Dunn TM, Gibbs J, Whitney N, Starosta A. Prevalence of orthorexia nervosa is less than $1 \%$ : Data from a US sample. Eat Weight Disord. 2017;22(1):185-92.

40. Segura-García C, De Fazio P, Sinopoli F, De Masi R, Brambilla F. Food choice in disorders of eating behavior: Correlations with the psychopathological aspects of the diseases. Compr Psychiatry. 2014;55(5):1203-11. 